\title{
Experimental Study of the Fire Behaviour on Flat Roof Constructions with Multiple Photovoltaic (PV) Panels
}

\author{
Kristensen, J. Steemann; Jomaas, Grunde
}

Published in:

Fire Technology

Link to article, DOI:

10.1007/s10694-018-0772-5

Publication date:

2018

Document Version

Peer reviewed version

Link back to DTU Orbit

Citation (APA):

Kristensen, J. S., \& Jomaas, G. (2018). Experimental Study of the Fire Behaviour on Flat Roof Constructions with Multiple Photovoltaic (PV) Panels. Fire Technology, 54(6), 1807-1828. https://doi.org/10.1007/s10694-018$0772-5$

\section{General rights}

Copyright and moral rights for the publications made accessible in the public portal are retained by the authors and/or other copyright owners and it is a condition of accessing publications that users recognise and abide by the legal requirements associated with these rights.

- Users may download and print one copy of any publication from the public portal for the purpose of private study or research.

- You may not further distribute the material or use it for any profit-making activity or commercial gain

- You may freely distribute the URL identifying the publication in the public portal

If you believe that this document breaches copyright please contact us providing details, and we will remove access to the work immediately and investigate your claim. 


\title{
Experimental Study of the Fire Behaviour on Flat Roof Constructions with multiple PV panels
}

\author{
J. Steemann Kristensen*,1,2 and G. Jomaas ${ }^{1,2}$ \\ ${ }^{1}$ Dept. of Civil Engineering, Technical University of Denmark, 2800 Kgs. Lyngby, Denmark. \\ ${ }^{2}$ School of Engineering, BRE Centre for Fire Safety Engineering, University of Edinburgh, Edinburgh EH9 3JL, \\ UK. \\ *j.kristensen@ed.ac.uk, +44 1316507209
}

\section{Acknowledgements}

The authors appreciate the experimental assistance received from research assistant Bjørn Skjønning Andersen from Technical University of Denmark and Richard Clemenceau, laboratory intern from ISTIA - École d'igénieurs de l'Université d'Angers (France). A special thank you goes to Kristian Schiang Frank and Jens Peder Jensen from Nordsjællands Brandskole for providing the experimental grounds and for their help with the construction of the roofing sections, the experiments and the extinguishment. The project was partially sponsored by IKEA Services AB. 


\title{
Experimental Study of the Fire Behaviour on Flat Roof Constructions with multiple PV panels
}

\begin{abstract}
Fire experiments were conducted on four mock-up roof constructions with an array of 6 photovoltaic (PV) panels on top to study the fire dynamics and flame spread behaviour under and beyond the roof segment covered by the PV panels. As it is customary to retrofit PV panels to existing warehouse roofs, where expanded polystyrene (EPS) and polyvinylchloride-based roofing membrane $\mathrm{B}_{\mathrm{ROOF}}(\mathrm{t} 2)$ is a typical roofing, the experiments were carried out on such installations, but with two mitigation solutions on top; $30 \mathrm{~mm}$ mineral wool or $40 \mathrm{~mm}$ polyisocyanurate (PIR). A wood crib was placed under the PV panels and ignited, which resulted in fire spread in all four cases. However, no self-sustained fire was observed beyond the area below the PV array. The EPS was ignited in both experiments with the PIR insulation due to thermal degradation of the protective material after approximately one hour. These full-scale experiments confirm that an initial fire underneath a PV installation can transform into a hazardous scenario due to the changed fire dynamics of the existing roof, where combustible construction materials can become fuel loads.
\end{abstract}

Keywords: Photovoltaic panels, Fire Experiments, Fire Dynamics, Mitigation

\section{Introduction}

The rapid increase of energy produced globally by photovoltaic (PV) installations continued in 2016, with a significant increase of $75 \mathrm{GW}$, to a total of $303 \mathrm{GW}$ [1]. In the US, an increase of $127 \mathrm{MW}$ was made solely by three shopping malls and a real estate company [2], indicating a solid commercial interest in PV power. A 58\% price drop since 2012 [3] and protection from changing energy costs, are reasons for the increased popularity of the PV installations. Flat roofed buildings, such as warehouses or industrial production buildings, are particularly suitable for PV installations due to their large area and the fact that they are often elevated above the surrounding environment and thus capable of utilising the full potential of the installation.

However, the addition of PV installations, and thereby large electric systems powered by an energy source that cannot be turned off (the sun), introduces a new hazard that few buildings have been designed for. In Italy alone, $800 \mathrm{PV}$ related fires occurred in 2012, after which it decreased to 600 and 469 fires in the following two years due to changed regulations [4]. Cancelliere [5] created a good overview of the issues related to the installation of PV arrays, where especially sections dealing with the cause of ignition and the propagation of the fire are of interest. The consensus seems to be that electrical malfunctions cause the initial fire on the roof constructions [6, 7, 8, 9]. Grant [10] described seven PV related fires in the US that all occurred due to electrical malfunctions, but he writes that the cause of the initial fire could also occur due to: (1) an external exposure fire, (2) fire originating within the structure, or (3) a fire originating in the PV system. From a fire safety engineering point of view, PV arrays installed on flat roof constructions are probable for both cause 1 and 3, but the consequences of both scenarios are similar - a fire developing underneath or in the PV installation. With an uncertainty of the power of a possible short circuit it would be of limited interest to test a specific set-up, since the difference between ignition and no ignition for a controlled short circuit also depends on the many surrounding factors - the fire often occurs due to the wrong events at the wrong time. Despite the uncertainty of the ignition source the fires occur and therefore the following experiments and analysis will focus on the propagation of the fire in case of an ignition underneath a PV array placed on a flat roof construction.

Backstrom and various co-authors carried out a series of projects at Underwriters' Laboratories, where they, based on UL1703 and UL790, tested how the introduction of PV panels or benchmark tests with non-combustible panels influenced the classification of different roof coverings [11-13]. The project focused on domestic installations on sloped roofs and how to prevent the installation to influence an existing fire [14]. They measured the maximum temperatures and heat fluxes and compared it with the 
critical heat flux for various roofing materials [14], and they came up with, and tested different mitigation solutions to prevent the fire from propagating underneath the panels [15-17].

Cancelliere and Liciotti [18] compared the reaction to fire for four different PV backsheets by the use of the Italian standards UNI 8957 and UNI 9174. The four backsheets obtained respectively the best and second best reaction to fire rating on a scale with five steps. Likewise, recent parametric studies [19] have showed that the PV panel itself only contains a limited amount of combustible materials such as a thin polymer based backsheet and combustible encapsulate materials. When ignited, the materials increase the heat flux towards the subjacent roof surface for a very short period because of the thin combustible layers and thereby limited time of combustion [19]. Given these points, the importance of the combustible materials in the main PV panel might be insignificant with respect to the propagation of the fire, - not to be mistaken with the fact that the PV panels probably are the main cause for the ignition, which leads to the fire.

Furthermore, the same recent parametric studies of the reflection of fire-induced heat underneath photovoltaic arrays [19] have shown that the reflected heat, combined with the deflected flame, represents an additional heat source that increases the total heat flux towards the top of the roof construction significantly. It was found that the additional heat, and thereby the PV panel, could make the difference between whether or not a roofing membrane was ignited.

The purpose of the current full-scale experiments was therefore to verify that the installation of a PV array increases the area where to the fire propagates. Based on the issues described above it was decided to make four full scale experiments to test: (1) If and how the fire would propagate underneath a PV array. (2) If the fire propagates outside the array. Furthermore, different mitigation solutions were tested to see if they could prevent ignition if they were placed on top of an existing expanded polystyrene (EPS) insulated roof construction.

\section{Experimental set-up}

The experimental set-up is divided into a description of the ignition source and a description of the four mock-ups used for the experiments.

\subsection{Source of ignition}

Although most PV related fires are assumed to occur due to an electrical malfunction, it was decided to ignite each mock-up by the use of a wood crib to ensure a similar source of ignition in all four experiments. The cribs were made of medium-density fibreboard (MDF) sticks with the dimension of $16 \mathrm{~mm} \times 16 \mathrm{~mm} \times 160 \mathrm{~mm}$ and a heat of combustion of $18.4 \mathrm{~kJ} / \mathrm{g}$. Each wood crib consisted of six layers with four sticks and was constructed according to McAllister [21], whose equations were also used to calculate the maximum theoretical heat release rate (HRR) of $30 \mathrm{~kW}$ for the cribs. An experimental HRR was determined by measuring the mass loss rate of four wood cribs. Two of the wood cribs were tested on a non-combustible surface, whereas the other two wood cribs were tested on top of the two mitigations solutions to screen if they influenced the mass loss rate, which was not the case. 


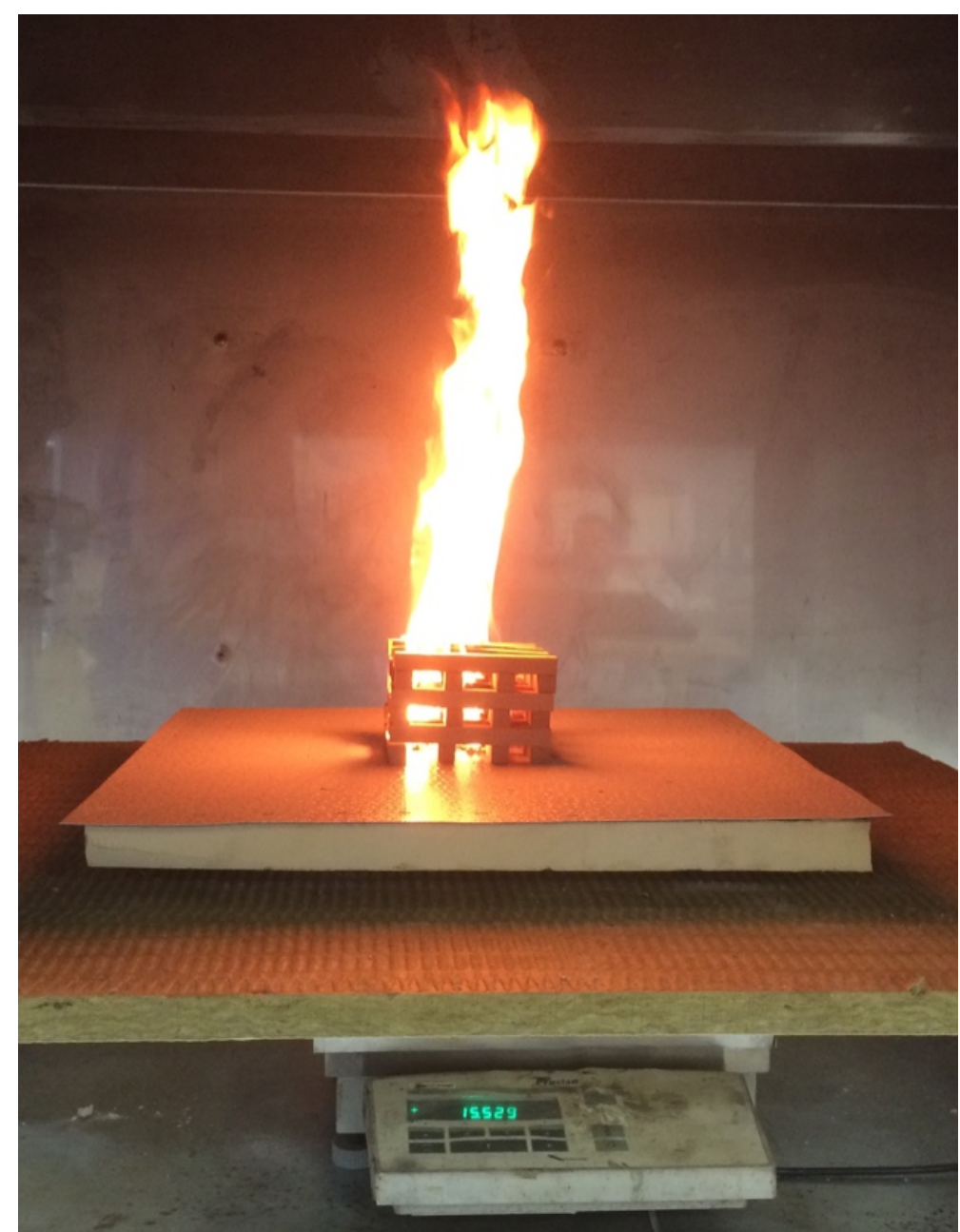

Figure 1 - Measurement of mass loss rate of the wood crib. From bottom to top: Scale, Mineral wool for protection of the scale, $40 \mathrm{~mm}$ PIR insulation, PVC-based roofing membrane, and wood crib.

\subsection{Design of the mock-ups}

A total of four full scale experiments were performed and the two kinds of mitigation layers, seen in Table 1 were tested. The mock-ups used for the experiments all consisted of three components as seen in Fig. 2; The existing roof construction, a mitigation solution, and vertical protection preventing ignition of the roof construction from the side of the mock-up. All of the roof constructions were built on top of a simple wood frame that made it possible to move each mock-up. The existing roof construction consisted of a self-supporting metal sheeting, $150 \mathrm{~mm}$ EPS insulation and a $\mathrm{B}_{\mathrm{ROOF}}(\mathrm{t} 2)$ classified polyvinylchloride-based (PVC-based) roofing membrane with a critical heat flux, $\mathrm{q}_{\text {crit, }}$ of $6.6 \mathrm{~kW} / \mathrm{m}^{2}[20]$. The European classification $\mathrm{B}_{\mathrm{ROOF}}(\mathrm{t} 2)$ is based on the test method EN 1187 and the classification EN 13501-5.

A mitigation solution was placed on top of the existing roof construction to prevent an ignition of the EPS insulation. The mitigation solution consisted of a mitigation layer (Table 1) and an additional layer of the aforementioned roofing membrane. Because the polyisocyanurate (PIR) insulation was manufactured with alufoil on both sides to decrease the influence of radiative heat towards the foam, it was decided to add a single layer of alufoil on top of the mineral wool in test T2. Also, the results of a bench scale test revealed a decrease of the temperature below the mineral wool due to the addition of alufoil [20], and this change made the PIR and the mineral wool more comparable from a pure heat transfer perspective. For the full-scale the experiments, it was decided only to test materials that were commercially available in Denmark, which is the reason for the different thickness of the two mitigation layers. All layers were mechanically fixed by the use of $32 \mathrm{~mm}$ metal discs and $6 \mathrm{~mm}$ self-tapping screws. 
Table 1 - Overview of the four test set-ups respectively mineral wool (MW) and polyisocyanurate (PIR) insulation.

\begin{tabular}{c|c|c|c} 
Test \# & Area of mock-up & Mitigation material & Wind \\
\hline T1 & $2.4 \mathrm{~m} \times 6.0 \mathrm{~m}$ & $40 \mathrm{~mm}$ PIR & None \\
T2 & $2.4 \mathrm{~m} \times 6.0 \mathrm{~m}$ & $30 \mathrm{~mm} \mathrm{MW} \mathrm{w/alu}$ & None \\
T3 & $4.8 \mathrm{~m} \times 6.0 \mathrm{~m}$ & $40 \mathrm{~mm} \mathrm{PIR}$ & Mild \\
T4 & $4.8 \mathrm{~m} \times 6.0 \mathrm{~m}$ & $30 \mathrm{~mm} \mathrm{MW}$ & Mild
\end{tabular}

\$: With a layer of alufoil on top of the mineral wool.

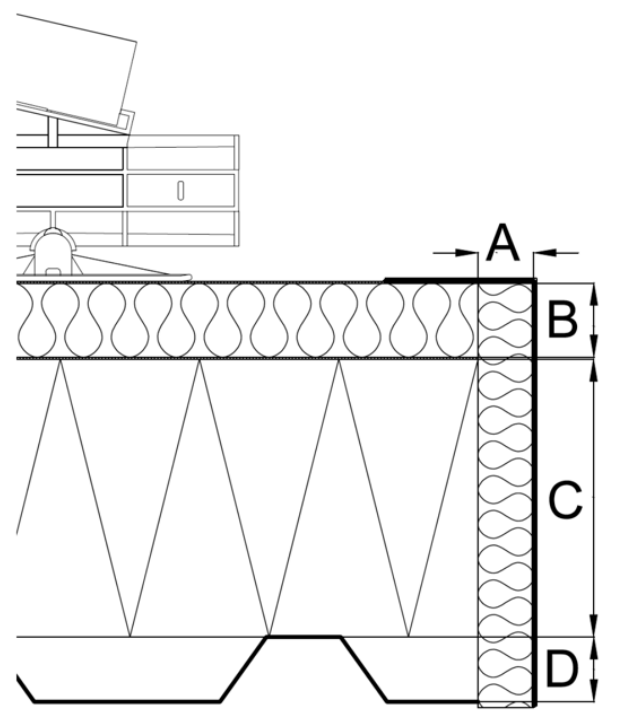

Figure 2 - Sectional view of the roof construction underneath the PV installation. A: Vertical protection layer of $30 \mathrm{~mm}$ mineral wool fastened with a $1 \mathrm{~mm}$ metal sheeting. B: The mitigation layer and a layer of PVC-based roofing membrane. The mitigation layer for each test can be seen in tab. 3.1. C: Insulation on the existing roof construction - 150 mm EPS insulation with a layer of PVC-based roofing membrane. D: Self-supporting metal sheeting with a height of $35 \mathrm{~mm}$. Parts of the used mounting system and a PV panel can be seen on top of the construction.

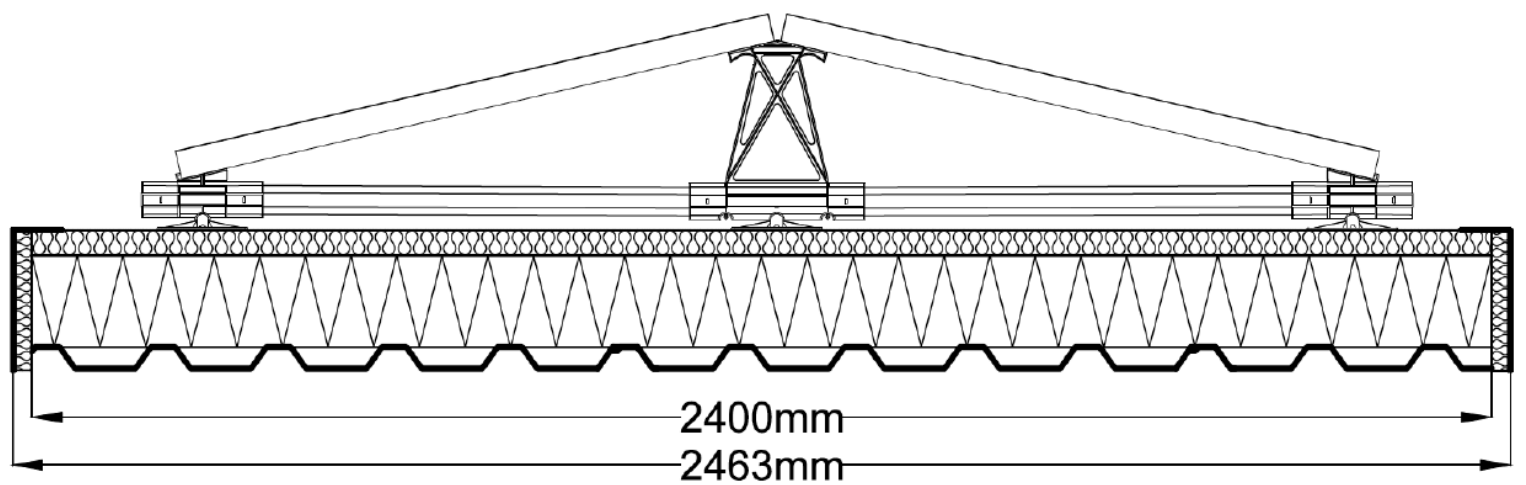

Figure 3 - Sectional cut of experiments T1 and T2. Experiments T3 and T4 were identical except from the width of the roof construction. 


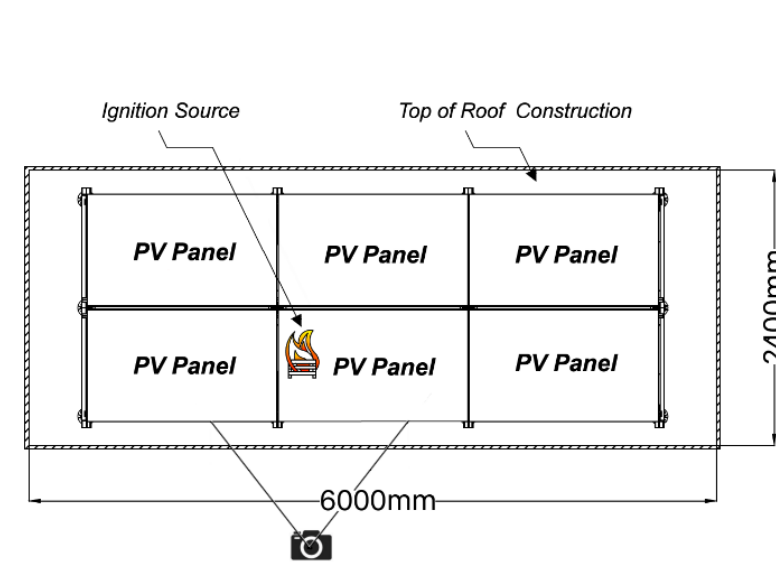

a) T1 and T2. The ignition source was placed underneath the junction box of the PV panel.

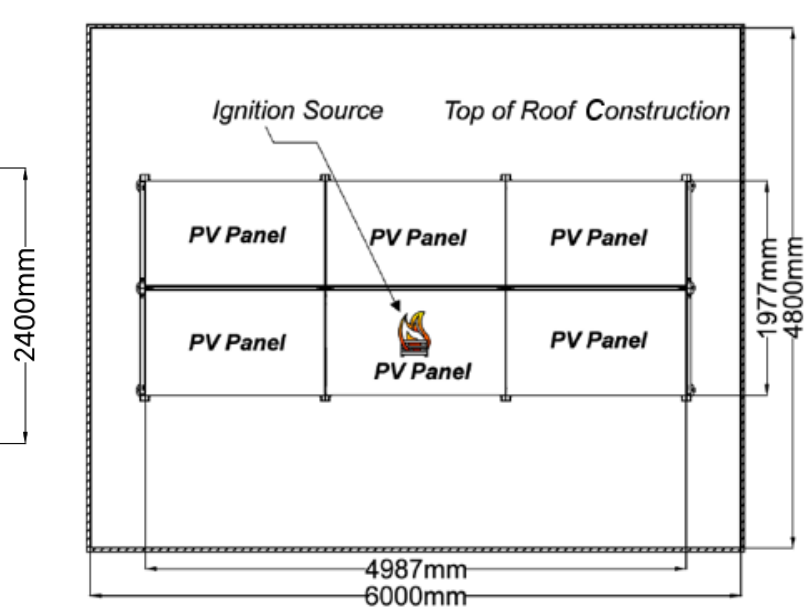

b) T3 and T4. The ignition source was placed underneath the centre of the PV panel.

Figure 4 - Top view of the two different experimental setups. The drawings are not to scale and the ignition sources are larger than the actual size.

The four experiments were conducted two different test days resulting in slightly different weather conditions as seen in Table 1. Six fully functional PV panels, each with the dimensions of $1.7 \mathrm{~m} \times 1.0 \mathrm{~m}$, were installed in the centre of all four mock-ups as seen from the three drawings in Fig. 4. The mounting system used for the installation of the PV panels was made of aluminium beams and plastic supports elevating the PV panels $32 \mathrm{~cm}$ in the centre and $9 \mathrm{~cm}$ on each side of the array. Where the main purpose of the first test round (T1 and T2) was to examine whether the fire propagated underneath the PV array, it was also possible to test if the fire propagated outside the array in the second test round (T3 and T4) where the area of the mock-ups were doubled as seen from Table 1 and Fig. 4.

Thermocouples were installed underneath the second layer of roofing membrane, on top of the EPS insulation and thereby in-between the two components of layer C in Fig. 2. In the first test round (T1 and T2) the thermocouples were placed along a horizontal and a vertical line intersecting underneath the point of ignition. In experiment $\mathrm{T} 3$ and $\mathrm{T} 4$, the temperature underneath the mitigation layers were measured with 20 type-K thermocouples located as seen from Fig. 5.

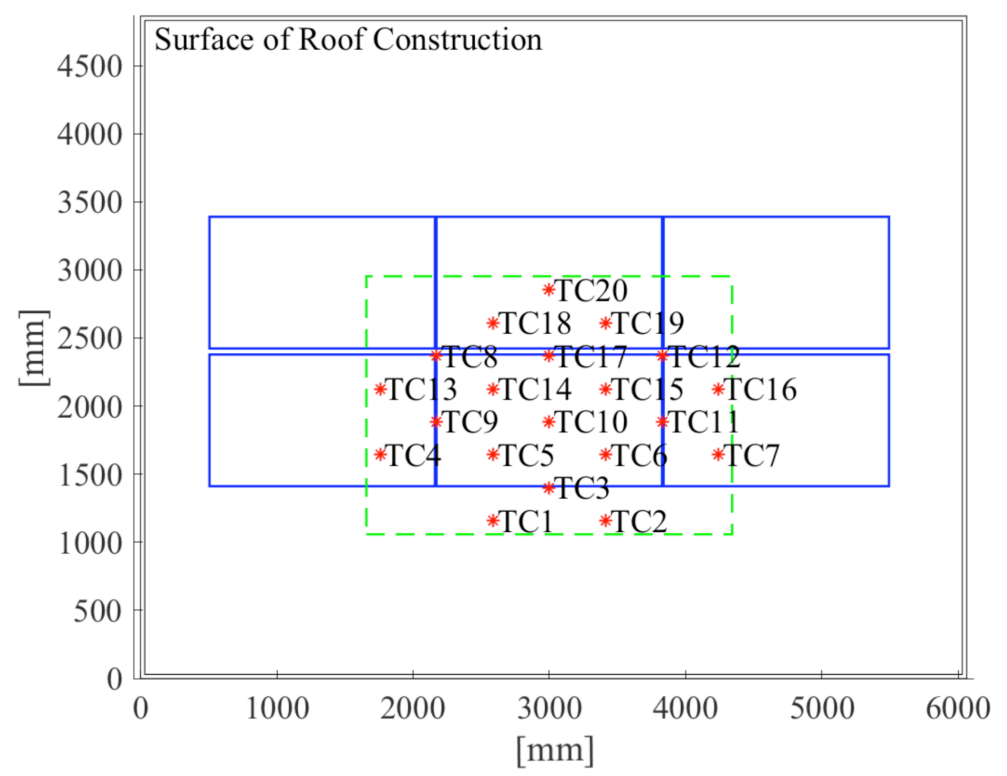

Figure 5 - Top view of the position of thermocouples (TC\#) in experiment T3 and T4. The six blue squares mark the position of the PV panels. The dotted green line defines the view used in Figs. 13 and 14. 


\section{Results}

3.1 Source of ignition

The four measurements of the mass loss rate did not reveal any significant difference between the experiments made on top of a non-combustible material, and the two mitigation solutions T3 and T4. Based on the mass loss rate for the four experiments, a heat release rate of $23 \mathrm{~kW}$ was calculated. In addition, the experiments also constituted another important observation. The two separated mitigation solutions are shown in Fig. 6 and it can be seen that neither the roofing membrane nor any of the mitigation materials were affected by the heat from the ignition source outside a diameter of approximately $20 \mathrm{~cm}$. The relatively small area affected, compared to the side length of the wood crib, indicated that the critical heat flux for flame spread across the roofing membrane used for the experiments was higher than the heat flux created by the wood crib alone. Thus, under normal circumstances (i.e. without PV panels), a fire of this size would not spread across the roofing membrane on top of PIR or mineral wool.

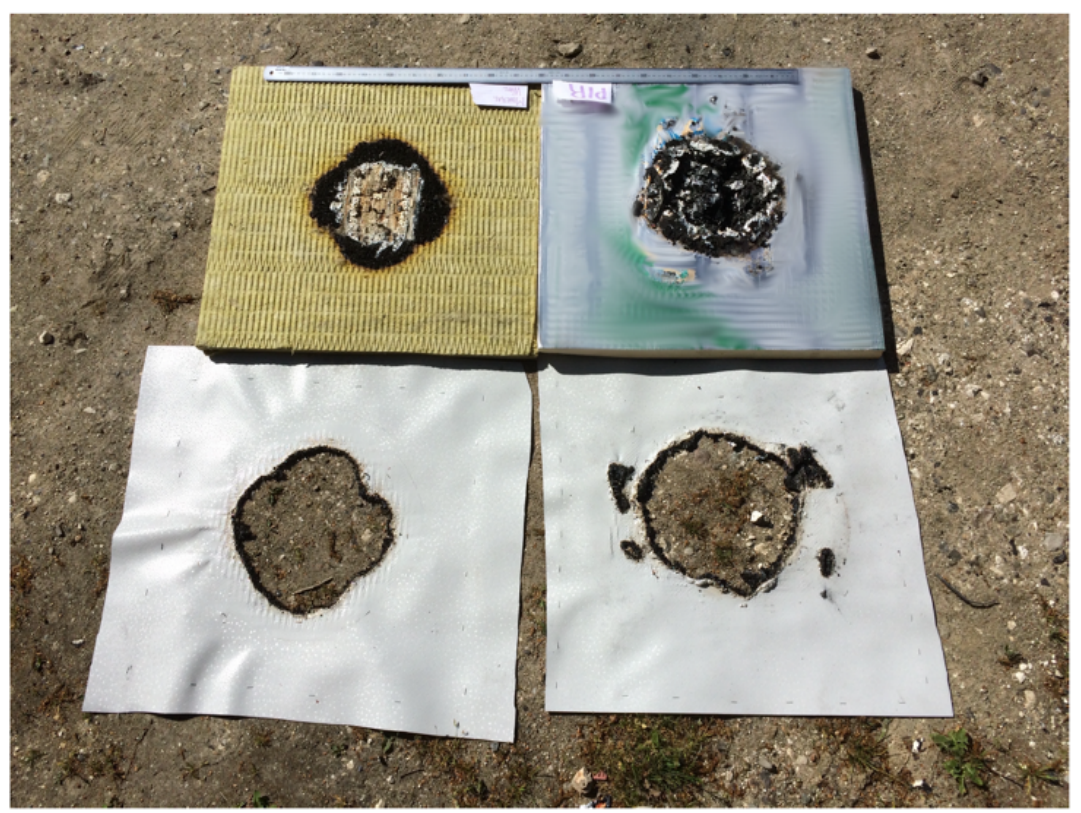

Figure 6 - Two of the mass loss experiments were carried out with a $60 \mathrm{~cm} \times 60 \mathrm{~cm}$ section of a mitigation solution with a mitigation layer of either mineral wool (upper left) or PIR insulation (upper right) and the roofing membranes (front). An area with the width of approximately $1 / 3$ of the total width was affected by the wood crib fire in all four experiments, defining the domain/distance where the heat from the wood crib can ignite the surrounding construction materials.

\subsection{Full Scale Experiments - initial propagation}

Despite the different wind conditions and the slight modification of the position of the ignition source, as seen in Fig. 4, the initial ignition of the roof construction occurred almost similar in all four experiments. Figure 7 shows the relevant frames of the ignition phase from experiment T2, where the wood crib was placed underneath the junction box and thereby next to the mounting system's transversal aluminium beam. As seen from Fig. 7 a, the limited amount of wind resulted in only vertical propagation of the fire inside the wood crib and no horizontal flames along the top of the roof construction. In the following frames in Figs. $7 \mathrm{~b}$ to d, it is seen how the heat from the wood crib ignited an object underneath the backside of the PV panel, whereupon the object dropped towards the top of the roof construction and ignited the roofing membrane. In Fig. 7 e the continuing fire indicates sustainability. From Figs. $7 \mathrm{f}$ to $\mathrm{h}$ the fire propagates to a total of approximately $50 \mathrm{~cm}$ along the right side of the roofing membrane, which after the propagation continued below the rest of the PV panel. 


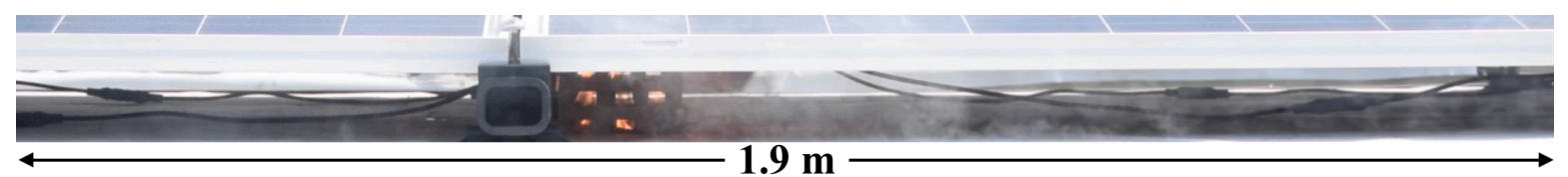

a) Time: $6: 56$ (frame 5 of 60 ), no ignition of membrane.

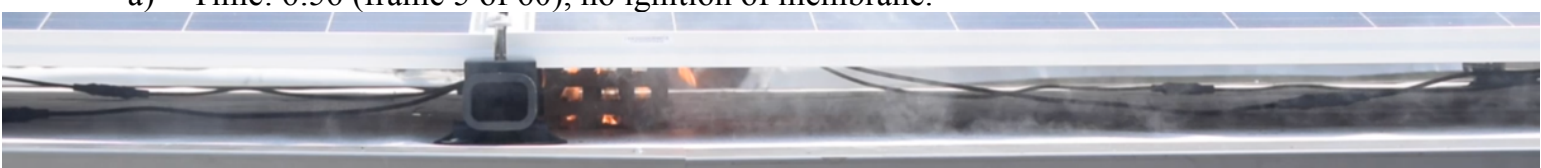

b) Time: 6:56 (frame 6 of 60), ignited material drops on right side of wood crib, below edge of PV panel.

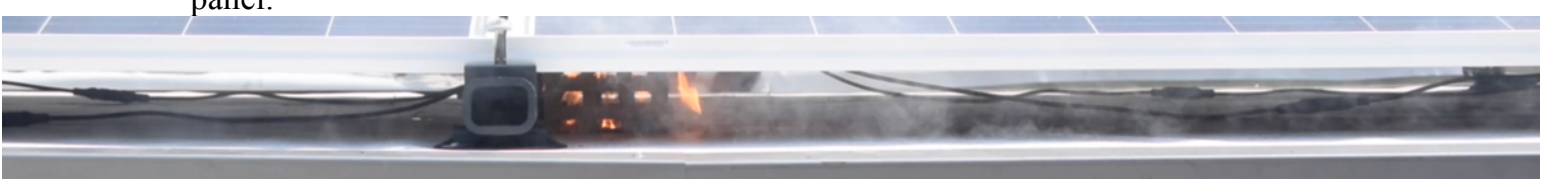

c) Time: 6:56 (frame 7 of 60), ignited material continues to burn before it hits the membrane.

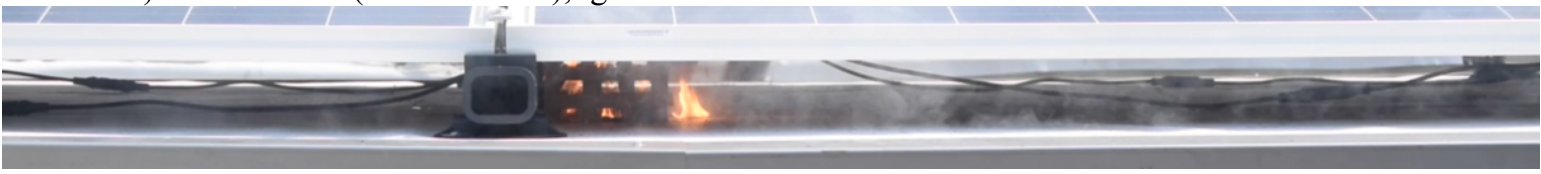

d) Time: 6:56 (frame 8 of 60), the falling, burning material ignites the roofing membrane.

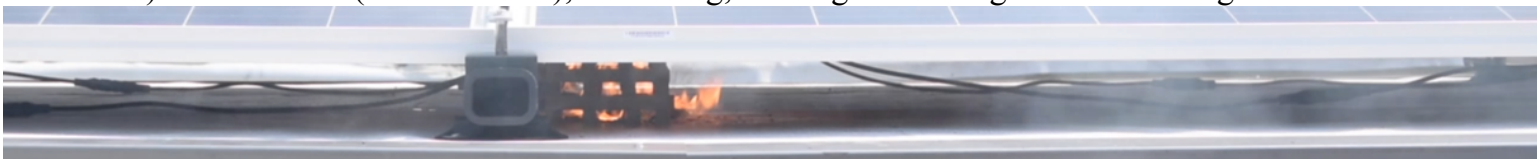

e) Time: 07:06, the fire is self-sustained.

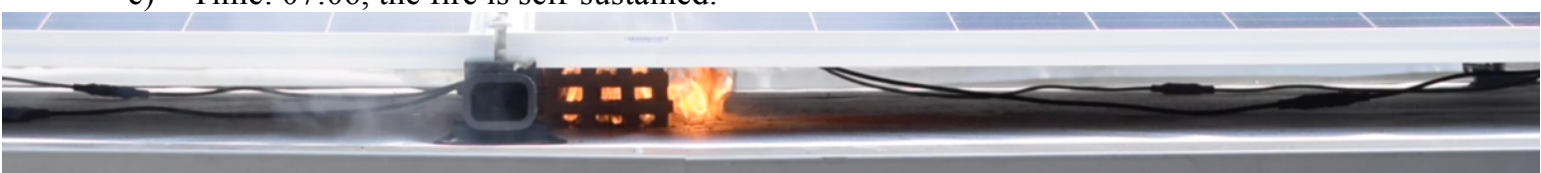

f) Time: 07:21, the fire propagates towards the right side.

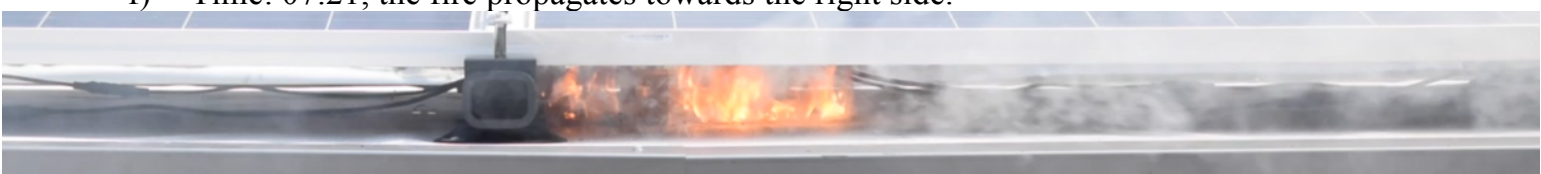

g) Time: 07:27, the fire propagates further towards the right side.

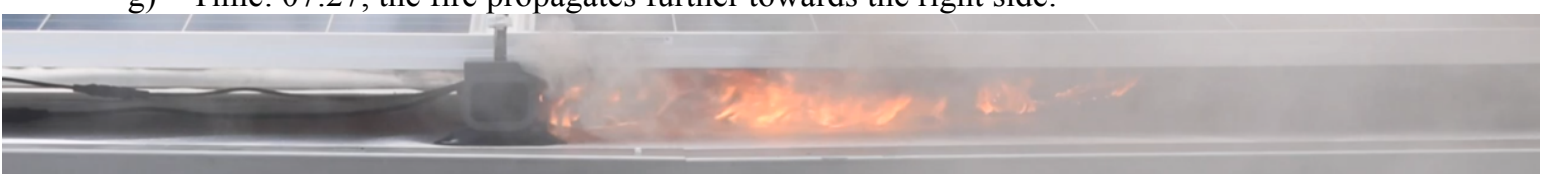

h) Time: 07:53, the fire ignites the cables underneath the panels.

Figure 7 - The ignition of the roofing membrane and initial propagation of the fire from experiment T2. The time is given in (min:s). The position of the wood crib and the viewpoint of the camera can be found in Fig. $4 a$.

Based on the video recordings of experiments T1 and T2, the distance between the flame fronts and the centre of the wood crib was estimated as a function of time from ignition of the wood crib, as seen in Fig. 8. For the two experiments, no spread occurred outside the source of ignition within the first 7 minutes, as the fire within the wood crib had to build up. This observation alone provides strong evidence for the crucial influence that the PV panels have on the fire dynamics and spread. The delay of approximately 3 minutes between the spread towards right side of the wood crib for test T1 and T2, occurred due a wind flow towards the left side of the picture in experiment T1. However, the inclination of the four plots in Fig. 8 are identical and equivalent to a spread velocity of approximately $20 \mathrm{~cm} / \mathrm{min}$. 


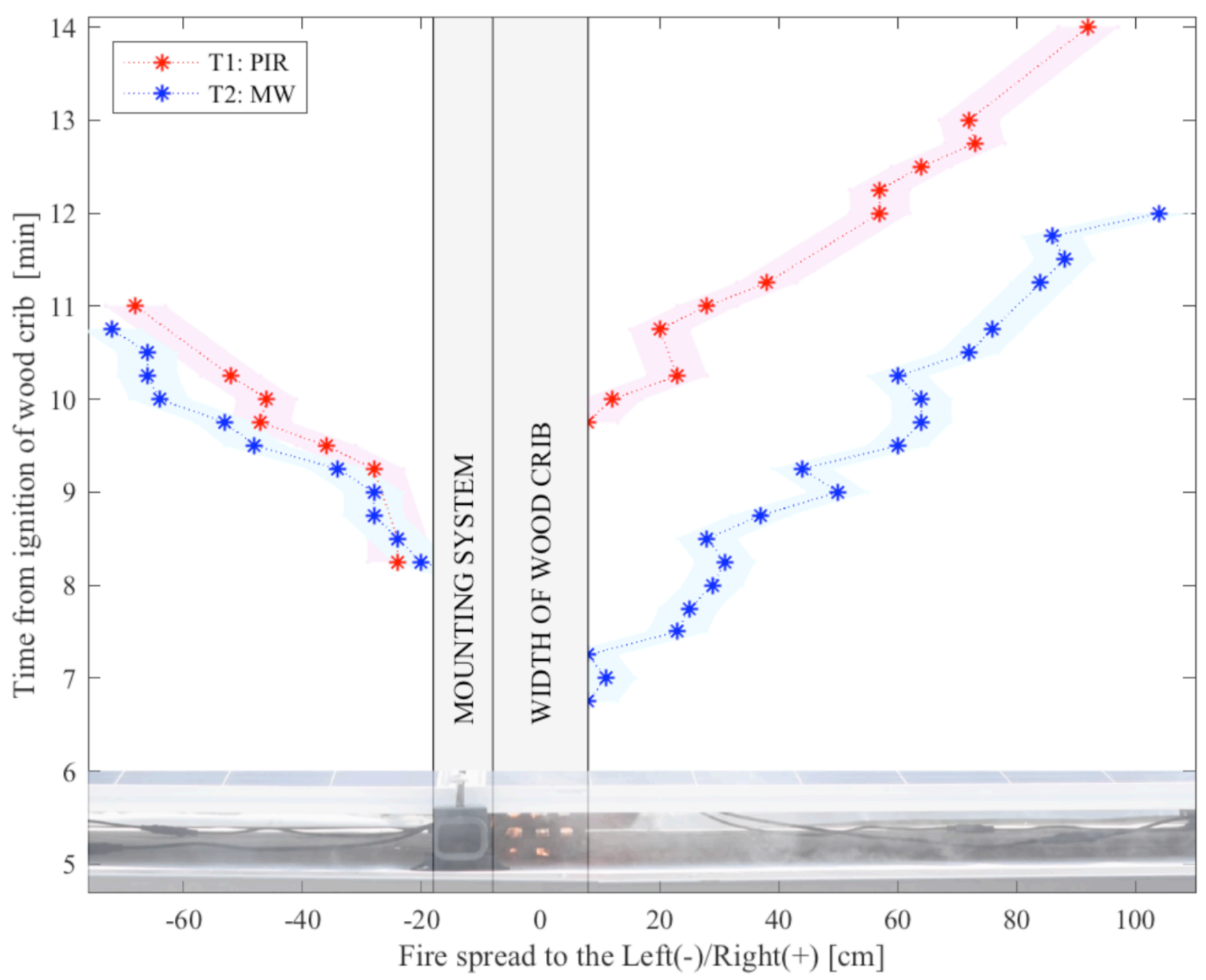

Figure 8 - Spread of fire as a function of time from ignition of the wood crib for experiment T1 (PIR) and T2 (MW). The fire did not spread beyond the ignition crib until around 7 minutes after ignition. The shaded areas indicate an uncertainty of $\pm 5 \mathrm{~cm}$. The position of the flame fronts were measured at the first frame for every 15 seconds, unless the view was obstructed by smoke. Please notice the swapped $x$ - and $y$-axis.

\subsection{Area of propagation}

The fire propagated underneath all six PV panels in all four experiments, as seen from experiment T3 in Fig. 9, which also shows the maximum spread of the fire outside the array. Experiments T1 and T2 showed that the fire hardly propagated outside the array, which was in line with the laboratory experiments with just a crib (Section 3.1). However, due to the limited size of the mock-ups, it was not possible to eliminate the influence of possible adverse edge effects that could reduce the growth of the fire near the edges. The increased area of experiments T3 and T4 made it possible to examine how the fire propagated outside the array. The maximum spread outside the array was approximately $1 \mathrm{~m}$, as seen from the picture in Fig. 9 and the two sketches in Fig. 10. The charred area in the left side of Fig. 9 shows the affected roofing membrane. The propagation outside the array did not occur due to propagation of the fire along the roofing membrane, but due to a wind-related deflection of the largest flames from the fire underneath the array.

Whereas the main PV panels did not contribute with a significant fuel load to the roof construction, all the plastic supports from the mounting system were ignited and burned until the fire were actively extinguished, as seen in Fig. 9.

The influence of the PV installation is thereby in accordance with the small scale laboratory experiments conducted by Kristensen et al. [19], which showed that the critical heat flux for spread could be reached with panels in place, but not without. 


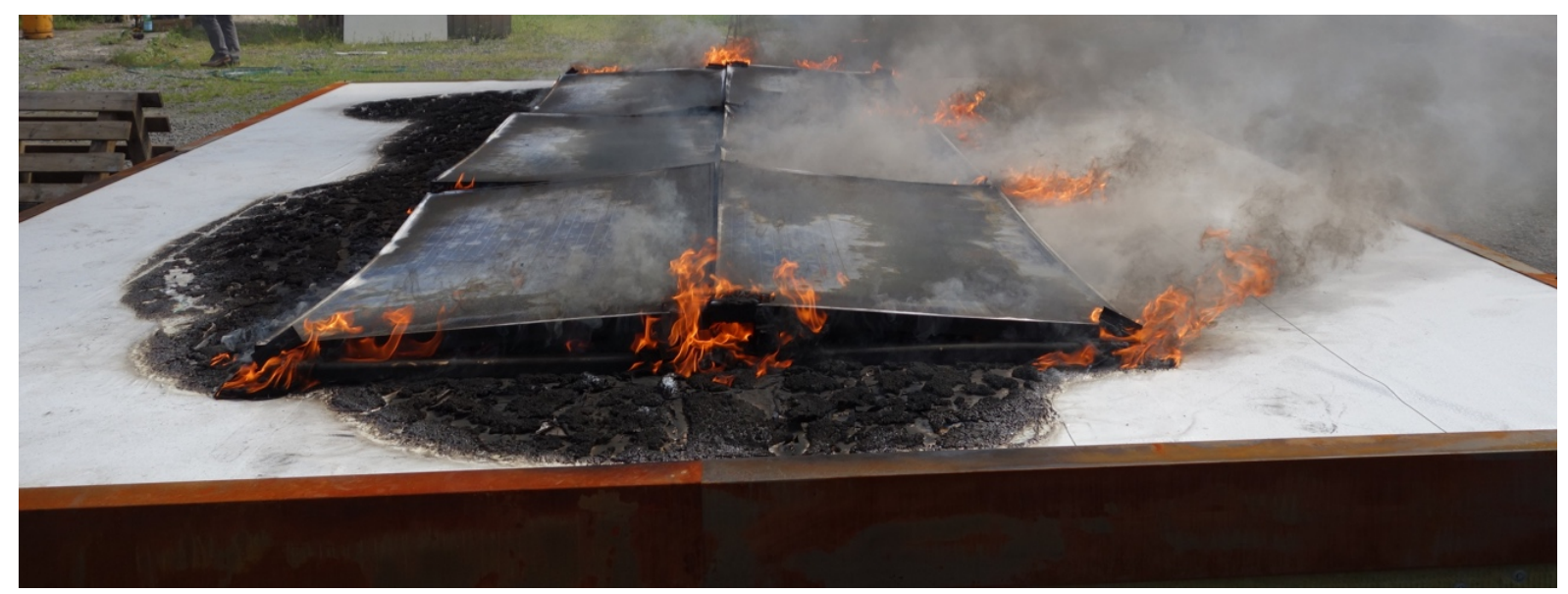

Figure 9 - Experiment T3. The whole area underneath the PV array was affected by the fire. Contrary to the picture, the dominant wind direction was from the right towards the left side of the picture as seen in Fig. 10 a.

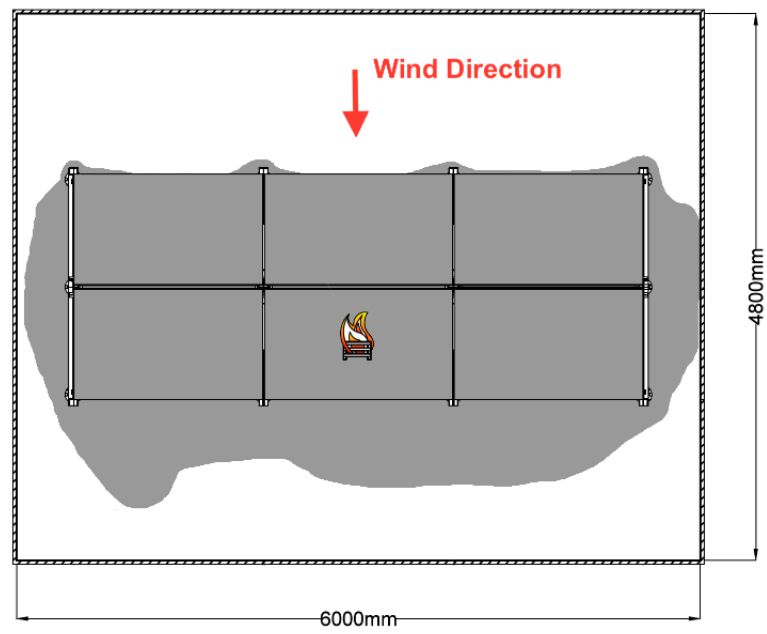

a) Experiment $\mathrm{T} 3$ with a mitigation layer of polyisocyanurate (PIR) insulation.

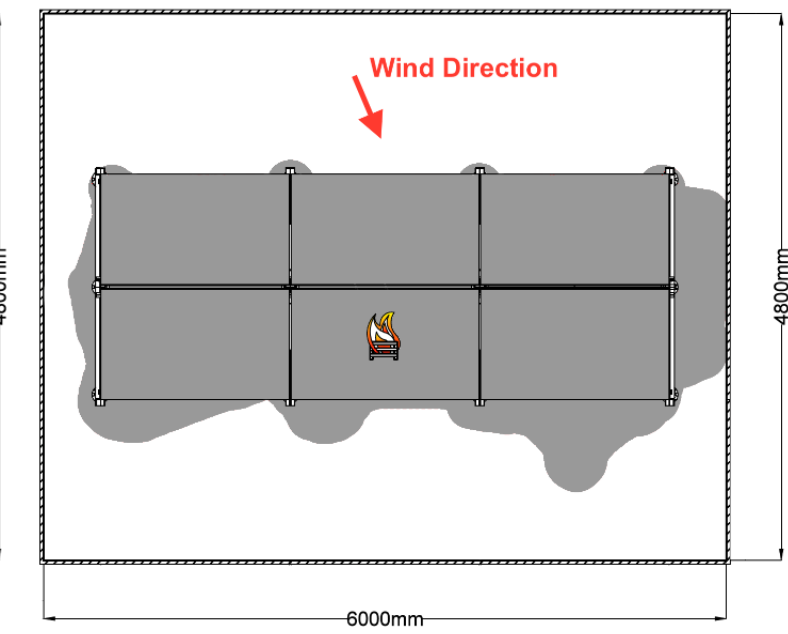

b) Experiment T4 with a mitigation layer of mineral wool (MW).

Figure 10 - Extent of fire propagation. The gray area indicates the roofing membrane affected by fire.

\subsection{Damage of the mitigation solutions}

Although the different mitigation layers had no direct influence on the combustion of the top roofing membrane, it was seen that the mitigation layers reacted differently to the heat from the burning membrane and the wood crib.

In both experiments with a mitigation layer of PIR insulation (T1 and T3) it was seen that the heat from the wood crib compromised the integrity of the product, resulting in a penetration of the mitigation layer as seen in Fig. 11. Upon penetration of the PIR insulation, the findings strongly suggest that the EPS below was ignited. This is supported by the sooted EPS insulation and melted carbonised areas in Fig. 13 a, as well as by smoke observations during the experiments. Further support for this comes from the temperature data presented in Section 3.5. The three areas with melted EPS insulation, marked by red arrows in Fig. 13 a, developed due to the heat from the burning plastic supports. 


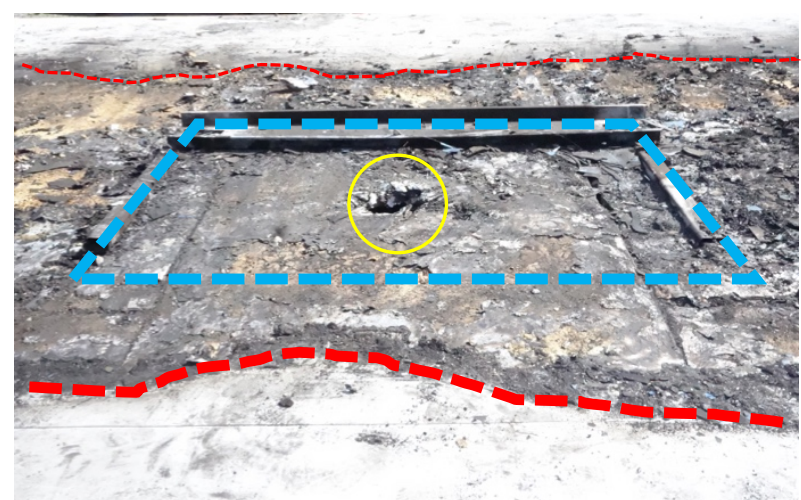

Figure 11 - Experiment T3. Part of mock-up cleared from leftovers and PV panel. Approximate width of the picture at centre: $1.8 \mathrm{~m}$. Yellow circle: penetrated PIR insulation at the point of ignition. Blue square (stippled lines): position of PV panel above point of ignition. Red stippled line: indicates the edge of the roofing membrane.

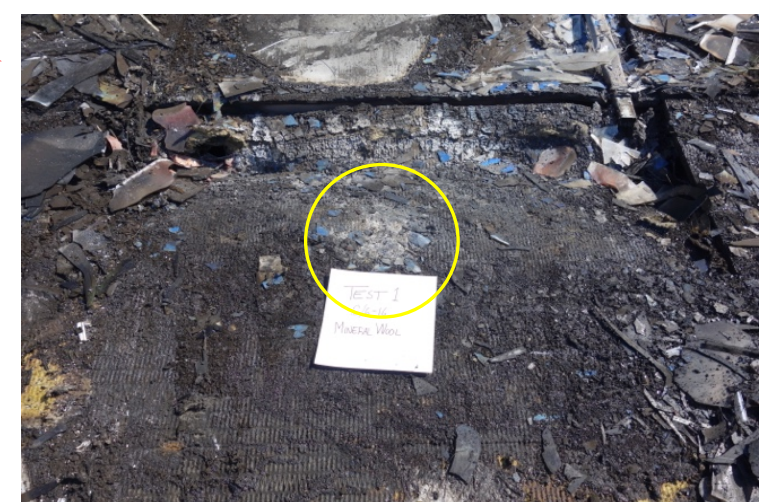

Figure 12 - Experiment T4. Part of mock-up cleared from leftovers and PV panel. Approximate width of the picture at centre: $1.2 \mathrm{~m}$. Yellow circle: Point of ignition without penetration of the mineral wool.

In the two experiments with a mitigation layer of mineral wool (T2 and T4) there were no physical damage of the mitigation layer, as seen from Fig. 12, which thereby separated the fire from the EPS insulation that were not ignited in both experiments. In spite of the non-ignited EPS insulation, it was still affected by the conductive heat transfer through the mineral wool, which melted the EPS. The damaged areas of EPS insulation were strongly dependent on whether the additional layer of alufoil was placed above the mineral wool. In experiment $\mathrm{T} 2$ only a circular area with a diameter of approximately $1 \mathrm{~m}$ was melted away, whereas most of the area underneath the PV array was affected in experiment T4, as seen from Fig. 13 b. In both experiments with a mitigation layer of mineral wool there was no sign of fire or combustion in the EPS insulation since there was no sooty or carbonised areas. 


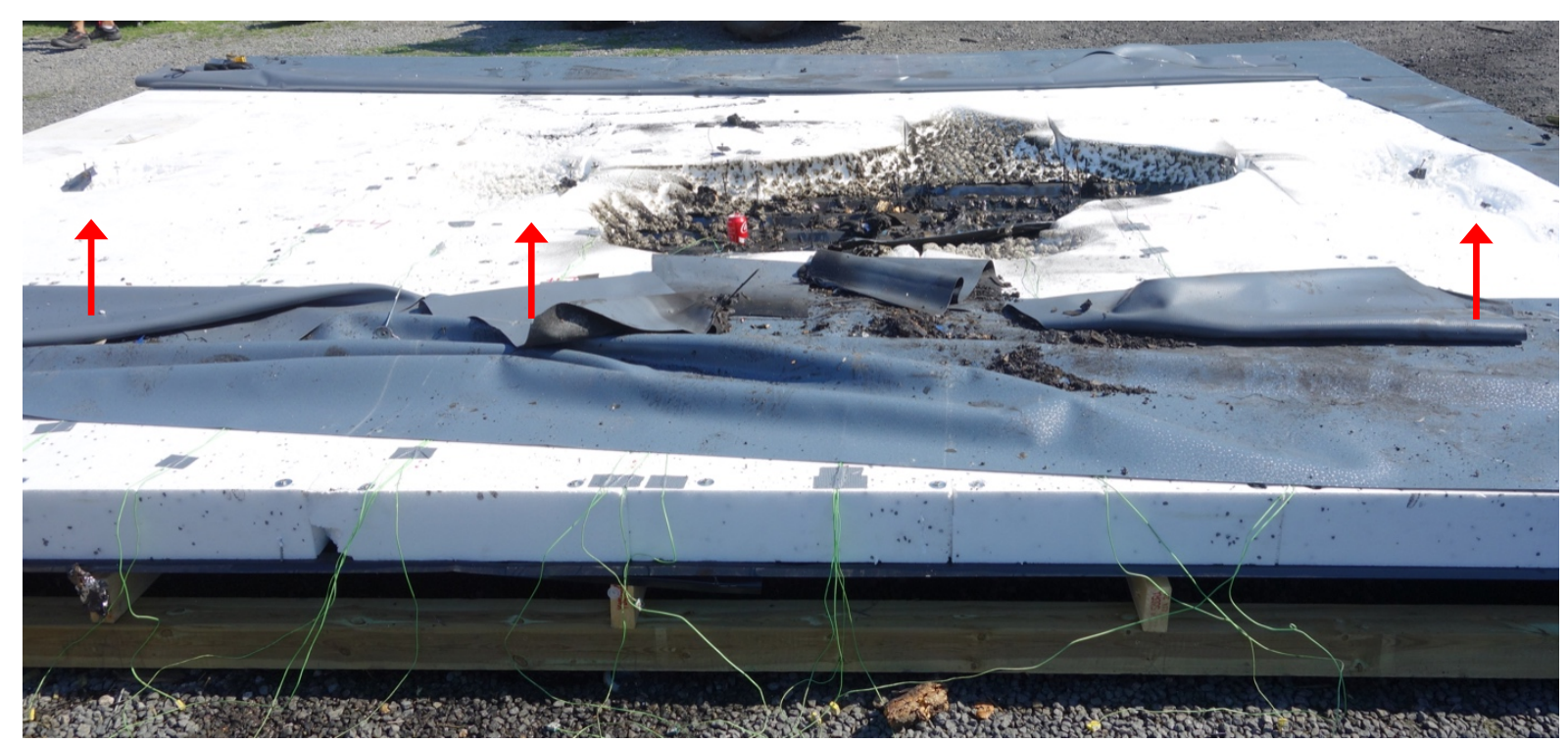

a) From experiment T3 (PIR insulation). The damaged area was limited due to extinguishment by fire fighters. Notice; 1) the sooty sides of the EPS insulation and the carbonised area in the centre of the hole. 2) The melted areas above the three red arrows. The observed smoke production and the recorded temperatures also support the postulation that the EPS ignited.

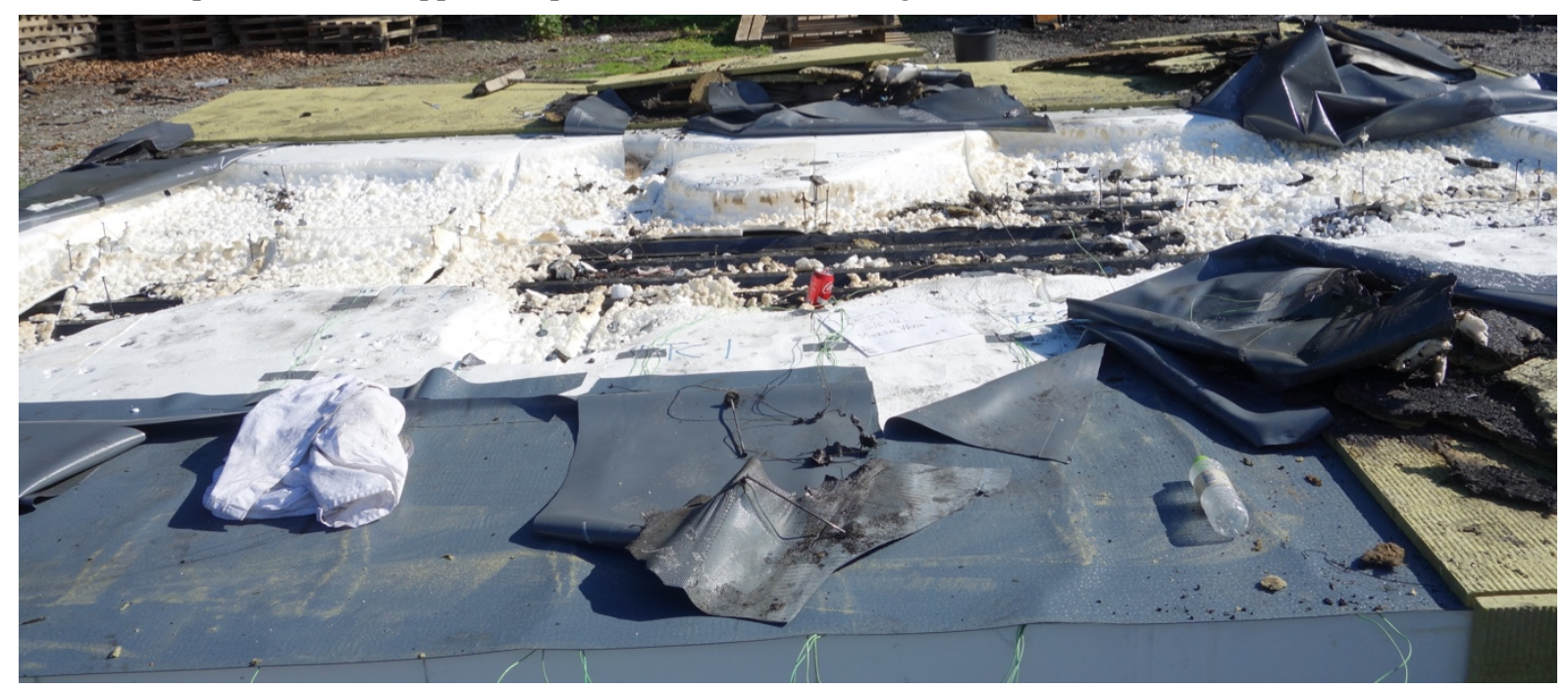

b) From T4 (mineral wool). The absence of soot on the EPS insulation, combined with the lack of smoke observations and the low recorded temperatures, suggests that no ignition occurred, and the damage of the EPS only happened due to the conductive heat transfer through the mineral wool.

Figure 13 - Overview of the damaged existing roof construction (layer C in Fig. 2) in a) experiment T3 (PIR insulation) and b) experiment T4 (Mineral wool). The red can was placed below the point of ignition in both pictures.

3.5 Development of temperature underneath the mitigation layers

Contour plots in Figs. 14 and 15 indicate the development of temperature on top of the EPS insulation at four (not-equivalent) instances for experiments T3 and T4. Although the contour plots in Figs. 14 and 15 only consists of four snapshots of the temperature development in experiment T3 and T4, they do indicate the main features for each test. According to the Ignition Handbook [22] piloted ignition for flame retarded EPS occurs at $366^{\circ} \mathrm{C}-405^{\circ} \mathrm{C}$ and auto-ignition at $470^{\circ} \mathrm{C}$. These temperatures were only measured in experiment $\mathrm{T} 3$ due to the earlier mentioned thermal degradation and penetration of the PIR insulation. Until the penetration of the PIR insulation, which occurs after 63 minutes, the maximum temperature below the mitigation layer in experiment $\mathrm{T} 3$ was $175^{\circ} \mathrm{C}$. Compared to the maximum measured temperature of $243^{\circ} \mathrm{C}$ underneath the mineral wool in experiment $\mathrm{T} 4$, the temperature was significantly lower. But it is noteworthy that the maximum temperatures were more than $100^{\circ} \mathrm{C}$ below the minimum temperature for piloted ignition. 


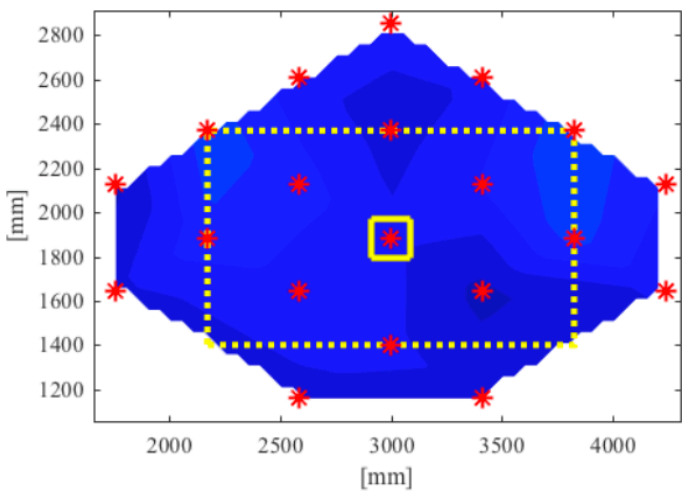

a) Time: $3600 \mathrm{~s}$.

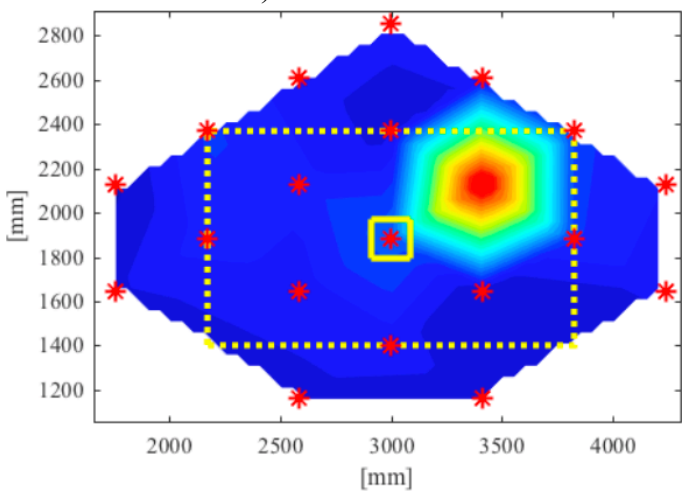

c) Time: $4130 \mathrm{~s}$.

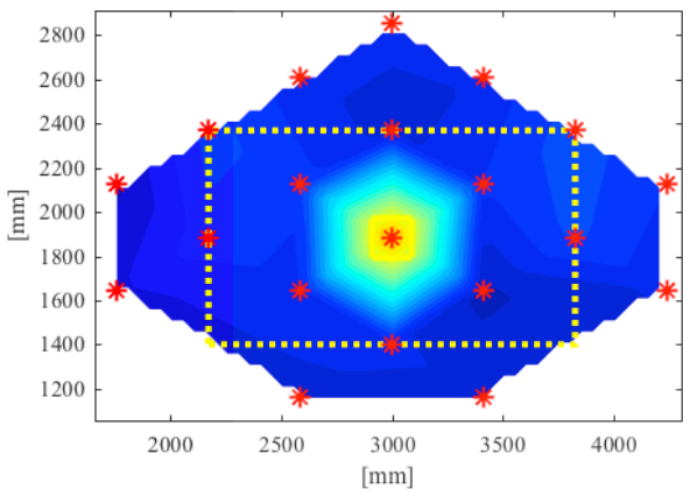

b) Time: $3821 \mathrm{~s}$.

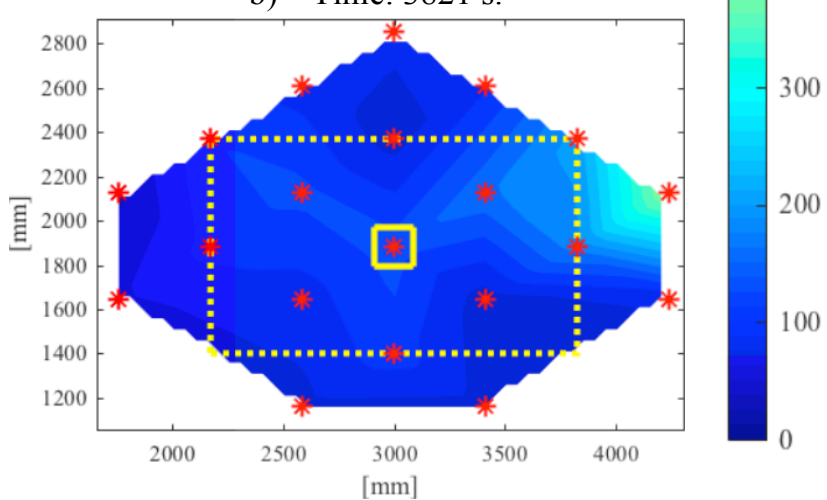

d) Time: $4548 \mathrm{~s}$.

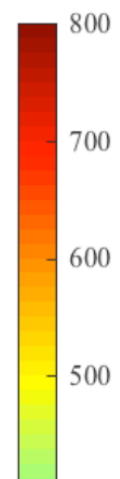

400

00

200

100

Figure $14-\mathrm{T} 3$. Development of the temperature underneath the PIR insulation in experiment T3. The different colours define the temperature in ${ }^{\circ} \mathrm{C}$. The solid yellow line marks the point of ignition and the dotted yellow line indicates the edges of the PV placed above the point of ignition. The functional thermocouples are marked with red dots.

The maximum temperature for experiment $\mathrm{T} 4$ occurs 34 minutes after the ignition, whereupon the temperature decreases, due to the lack of combustible materials on top of the construction, as seen from Fig. 15 d. In Fig. 14 the temperature is plotted after the penetration of the PIR insulation and indicates how the warmest area is travelling within the EPS insulation. The hottest area in Fig. 14 is moving from the point of ignition above thermocouple 10 (Fig. 14 a), towards thermocouple 15 (Fig. 14 b) and 13 (Fig. 14 c). None of the plotted temperatures in experiment T4 exceeds the above-mentioned temperature for piloted ignition of flame retarded EPS [22]. The lack of high temperatures is made on purpose to make a similar scaling between Figs. 14 and 15. Furthermore, the high temperatures only occurred for a few minutes near each thermocouple due to the limited mass of the combustible EPS insulation, as seen from Fig. 16. The short duration of the high temperatures in Fig. 16 indicates ignition and combustion of the EPS insulation. Due to the significant temperature increase and smoke development, it was decided to extinguish the experiment after 75 minutes, as this also enabled examination of the post-fire damages to the roof construction. 


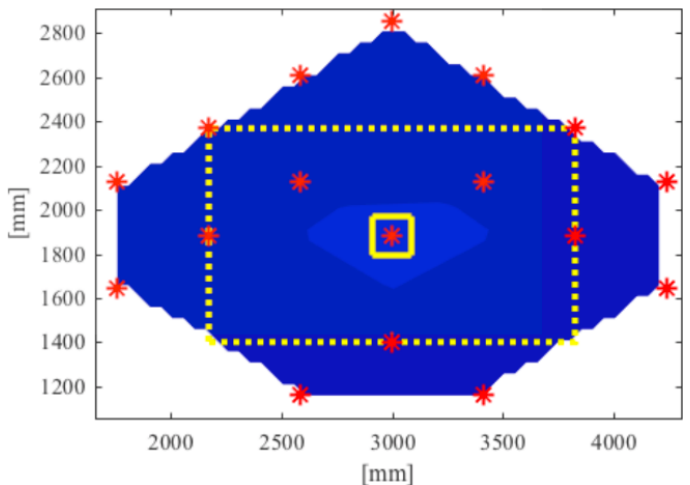

A) Time: $600 \mathrm{~s}$.

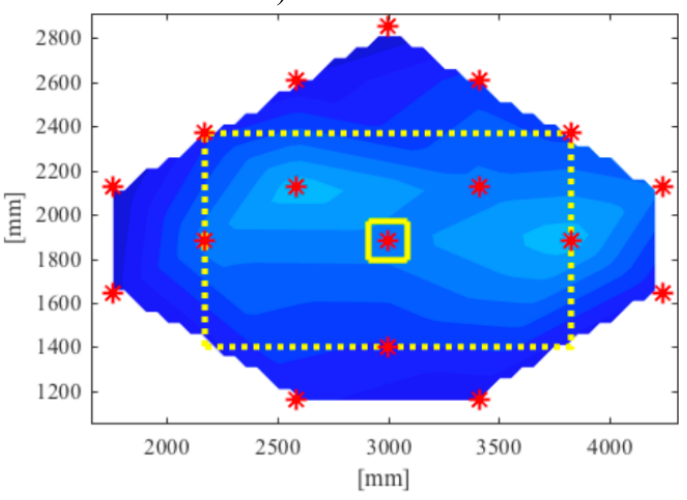

C) $1980 \mathrm{~s}$.

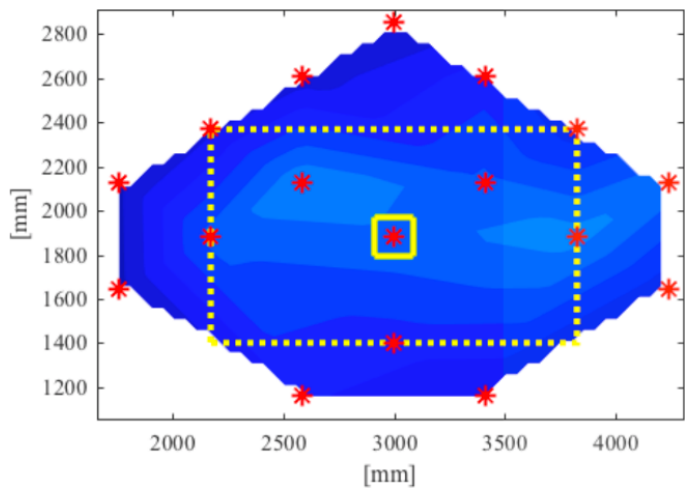

B) $1500 \mathrm{~s}$.

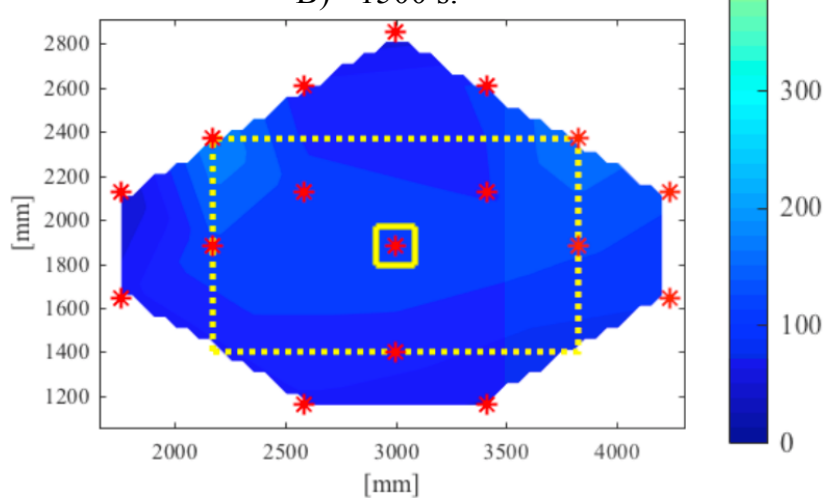

D) $3600 \mathrm{~s}$.

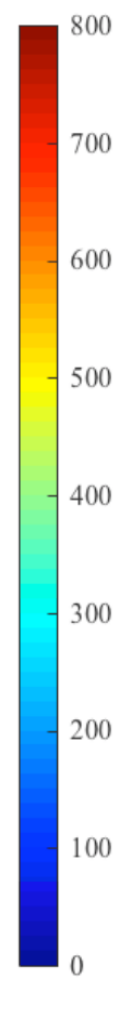

Figure 15 - T4. Development of the temperature underneath the mineral wool in experiment T4. The different colours define the temperature in ${ }^{\circ} \mathrm{C}$. The solid yellow line marks the point of ignition and the dotted yellow line indicates the edges of the PV placed above the point of ignition. The functional thermocouples are marked with red dots.

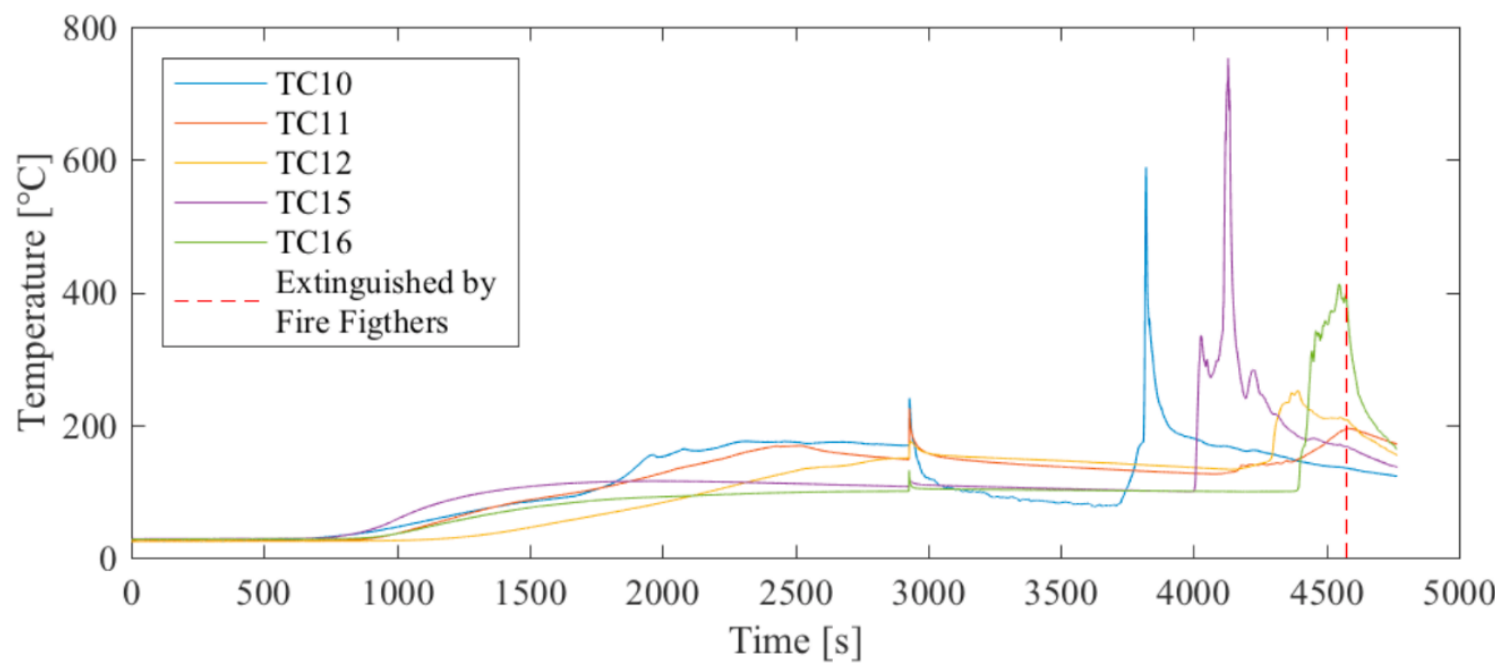

Figure $16-\mathrm{T} 3$. Temperatures measured in selected thermocouples (TC). The number of the TC refers to the position seen in Fig. 5. 


\section{Conclusion}

The four experiments covered herein demonstrated, that the propagation of fire on a roof construction with PV arrays were limited by the area of the arrays. The maximum propagation outside the array was not influenced by the type of mitigation layer, but the velocity and direction of the wind. For the used PVC based roofing membrane it was thereby seen that the installation of PV arrays, transformed the fire related properties due to the changed fire dynamics. The results of earlier parametric studies, dealing with re-radiation of the heat underneath PV panels, are thereby confirmed.

$40 \mathrm{~mm}$ PIR insulation (T1 and T3) and $30 \mathrm{~mm}$ mineral wool (T2(w/alu) and T4) were tested as mitigation layers to protect a subjacent layer of expanded polystyrene (EPS) from ignition, which partially succeeded for both solutions within an hour after ignition. Where the ignition of the EPS insulation in experiment T1 may have occurred due to ignition from the side of the mock-up, it was not the case in test T3. After one hour and three minutes, the mechanical properties of the PIR insulation in experiment T3 failed, the material was penetrated by the fire, and the EPS insulation was ignited. In both experiments with PIR insulation it was necessary to extinguish the fire by assistance from the fire fighters, indicating that a fire in the EPS insulation is sustainable in case of ignition, due to the fuel/airratio of the material. Contrary to experiment $\mathrm{T} 1$ and $\mathrm{T} 3$, the mineral wool in experiment $\mathrm{T} 2$ and $\mathrm{T} 4$ remained stable throughout the experiments. The mechanical stability and the maximum measured temperature of $243^{\circ} \mathrm{C}$ prevented an ignition of the EPS insulation.

The obtained results provide an increased understanding of the fire related risk introduced by the installation of PV arrays. The results indicate that the geometry of the PV installations has a significant influence on the propagation. The fire related risk of PV panels is thereby not only dependent on the new installation, - but also on the materials in the existing roof construction. Although the roofing membrane was classified as $B_{\mathrm{ROOF}}(\mathrm{t} 2)$ according to $\mathrm{EN}$ 13501, the fire propagated quickly due to the additional contribution of heat reflected by the PV panels. Solving the issue will require further studies within multiple fields of fire safety engineering, such as understanding; 1) how the materials used on existing roof constructions react to fire, when they are exposed to the abovementioned combined heat flux; 2) how the design of the PV installations, such as elevation and inclination of the panels and distance between individual arrays, influences the spread of fire; 3 ) how the components related to the PV installation, such as the mounting system, reacts to fire; and finally 4) how the spread of fire is affected by different weather conditions such as wind, which could accelerate the propagation even further.

In brief, these full-scale experiments confirm that an initial fire underneath a PV installation can transform into a hazardous scenario due to the changed fire dynamics of the existing roof, where combustible construction materials can become fuel loads and thereby increase the fire risk through increased consequences. Combined with the fact that introducing PV panels increases the probability of a fire, the overall risk in terms of probability times consequence can increase significantly unless properly managed through the use of the proper fire mitigation and fire management solutions. 


\section{References}

1. IEA International Energy Agency, (2017), 2016 Snapshot of Global Photovoltaic Markets, http://www.ieapvps.org/fileadmin/dam/public/report/PICS/IEA-PVPS_-_A_Snapshot_of_Global_PV_-_1992-2015_-_Final_2_02.pdf, visited 21/06/17

2. SEIA Solar Energy Industries Association, (2017), Solar Means Business 2016 - Tracking Solar Adoption by America's Top Companies, http://www.seia.org/research-resources/solar-means-business-2016, visited 21/06/17.

3. SEIA Solar Energy Industries Association, (2017), Solar Industry Data Solar Industry Growing at Record Pace, http://www.seia.org/research-resources/solar-industry-data, visited 21/06/17.

4. Fiorentini, L., Marmo, L., Danzi, E., and Puccia, V. (2015), Fires in photovoltaic systems: Lessons learned from fire investigations in Italy, URL: http://www.sfpe.org/?page=FPE_ET_Issue_99\&hhSearchTerms="issue+and+99", visited 21/06/17.

5. Cancelliere, P., (2014) PV electrical plants fire risk assessment and mitigation according to the Italian national fire services guidelines. doi:10.1002/fam.2290.

6. Zhao, Y., de Palma, J.F., Mosesian, J., Lyons, R., and Lehman, B. (2013), Line-line fault analysis and protection challenges in solar photovoltaic arrays, IEEE Transactions on Industrial Electronics, volume 60, DOI: 10.1109/TIE.2012.2205355

7. Brooks, B. (2012), The ground-fault protection blind spot: A safety concern for larger photovoltaic systems in the United States, http://www.solarabcs.org/about/publications/reports/blindspot/, visited 22/06/17

8. Pandian, A., Bansal, K., Thiruvadigal, D.J., and Sakthivel, S., (2015), Fire hazards and overheating caused by shading faults on photo voltaic solar panel, Fire Technology, volume 52, DOI: 10.1007/s10694-015-0509-7

9. Wohlgemuth, J.H. and Kurtz, S.R. (2012) How can we make PV panels safer? IEEE Photovoltaic Specialists Conference, Austin, Texas (ed. NREL).

10. Grant, C.C., (2010), Fire fighter safety and emergency response for solar power systems, The Fire Protection Research Foundation

11. Backstrom, B. and Tabaddor, M. (2009), Effect of Rack Mounted Photovoltaic Modules on the Fire Classification Rating of Roofing Assemblies, Underwriters' Laboratories, http://www.solarabcs.org/currentissues/docs/UL_Report_PV_Roof_Flammability_Experiments_11-30-10.pdf_visited 21/06/17.

12. Backstrom, B. and Sloan, D. (2012), Effect of Rack Mounted Photovoltaic Modules on the Fire Classification Rating of Roofing Assemblies - Phase 2, Underwriters' Laboratories, http://www.solarabcs.org/current-issues/docs/UL_Report_Phase2_1-30-12.pdf, visited 21/06/17.

13. Backstrom, B. and Sloan, D. (2012), Report of Experiments of Minimum Gap and Flashing for Rack Mounted Photovoltaic Modules Phase 4, Underwriters' Laboratories, http://www.solarabcs.org/current-issues/docs/UL Report_Gap_and Flashing_Exps 3-29-12.pdf, visited $21 / 06 / 17$

14. Backstrom, B and Sloan, D. (2012), Characterization of Photovoltaic Materials - Critical Flux for Ignition/Propagation Phase 3 , Underwriters' Laboratories, http://www.solarabcs.org/current-issues/docs/UL_Report_Critical_Flux_Experiments_1-16-12.pdf, visited 21/06/17.

15. Backstrom, B. and Tabaddor, M. (2009), Effect of Rack Mounted Photovoltaic Modules on the Fire Classification Rating of Roofing Assemblies - Demonstration of Mitigation Concepts, Underwriters' Laboratories, http://www.solarabcs.org/currentissues/docs/UL Report PV and Roof Flammability Mitigation 2-10-10.pdf, visited 21/06/17.

16. Backstrom, B. and Sloan, D. (2012), Considerations of Module Position on Roof Deck during Spread of Flame Tests - Phase 5 , Underwriters' Laboratories, http://www.solarabcs.org/current-issues/docs/UL_Report Module Reposition Experiments 7-24-12.pdf, visited 21/06/17.

17. Backstrom, B. (2013), Validation of Roof Configuration 2 Experiments Project 9, Underwriters' Laboratories, http://www.solarabcs.org/current-issues/docs/Validation_of_Roof_Configuration_2_Experiments.pdf, visited 21/06/17.

18. Cancelliere, P. and Liciotti, C. (2014), Fire Behaviour and Performance of Photovoltaic Module Backsheets, Fire Technology, volume 52.

19. Kristensen, J. S., Merci, B., and Jomaas, G. (2017), Fire-induced Re-radiation underneath Photovoltaic Arrays on Flat Roofs, Fire and Materials, Wiley, Accepted for publication

20. Kristensen, J.S. (2015), Fire Risk Assessment of Solar Cell Array Installations on Large Buildings: How to Protect the Building in Case of Fire? Tech. Rep., Technical University of Denmark (DTU), Department of Civil Engineering.

21. McAllister, S. and Finney, M. (2013), Effect of crib dimensions on burning rate, in Proc. of the Seventh International Seminar on Fire Explosion Hazards (ISFEH7), ISBN: 978-981-08-7724-8.

22. Babrauskas, V. (2014), Ignition Handbook, ISBN 0-9728111-3-3, p. 1069 